\title{
Study of enhancing thermo-hydraulic performance of turbulent flow inside a tube occupied with central cut twisting tapes
}

\author{
Khudheyer S. Mushatet ${ }^{1 *}$, Qais A. Rishak ${ }^{2}$, Mohsen H. Fagr ${ }^{1}$ \\ 1* Mech. Eng. Dept. University of Thi-qar, Nasseriya, Iraq; e-mail: khudheyersalim@ gmail.com \\ 2 Mech. Eng. Dept. University of Basra, Basra, Iraq; e-mail: qais_abed2000@yahoo.com
}

\begin{abstract}
The present 3D numerical study was performed to show the effects of the length of central cut twisting tape (CCTT) on the characteristics of thermodynamic and hydrodynamic fields when this tape is inserted inside a tube in which, air is flows in turbulent pattern. Central cut twisting tapes of the same cut ratio $(\mathrm{c}=\mathrm{C} / \mathrm{D})$ of 0.4 and four different length ratio $(\mathrm{LR}=1 / \mathrm{L})$ of $0.25,0.5,0.75$ and 1 were inserted in the tested tube that subjected to a uniform heat flux. The range of Reynolds number of air flow was $10000 \leq \mathrm{Re} \leq 40000$. Fluent in ANSYS 15 was used for problem designing, formulation and results obtaining in the present study. Finite volume method was the discretization method and tetrahedral type of mesh element was used. RNG k- $\varepsilon$ was chosen as the turbulent model. The obtained results showed that the increasing in Reynolds number leads to an increasing in Nusselt number and a decreasing in both friction factor and thermal performance factor. Also, these results cleared that the increasing in the length ratio of the studied type of twisting tape gives higher Nessult number, friction factors and thermal performance factor of $171.172,0.0932$ and 1.432 respectively.
\end{abstract}

Index Term-- Twisting tape, central cut, length ratio, cut ratio

\section{Introduction}

Using twisting tapes as a swirling flow generator has a wide range of applications in engineering fields due to the importance of this flow pattern in enhancing heat transfer. The technologies of achieving this enhancement have been developed, improved and widely applied in many applications of heat exchangers as chemical industry, refrigeration, reactors and process industry [1]. Generally, the twisting tape can be considered as the most important passive technique in the technologies of enhancing heat transfer. Twisting tapes have many advantages like easily installation, simple configuration, steady performance and low cost of manufacturing [2]. Through swirls generating, blockage and partitioning of the flow, the twisting tapes enhance the flow pattern in a manner that leads to an enhancement in heat transfer. Few researchers gave their attention to the central cut twisting tape and most of the published studies focused on using this type of twisting tapes, also known as center cleared twisting tape, with laminar flow. More attention and efforts are needed for studying this twisting tape type. The present effort focused on the using of different length central cut twisting tapes in turbulent flow. In general, many researchers gave their attention to studying and developing the twisting tapes. Rishak et al. [3] studied numerically the effects of the cut ratio of central cut twisting tape on thermal and hydrodynamic fields of air flow at Re from 10000 to 40000 in a tube of constant heat flux. Four cut ratios of $0.0,0.2,0.4$ and 0.6 were covered in their study. Their results introduced a direct relationship between this parameter and Nusselt number. Also, the cases of moderate cut ratio, 0.2 and 0.4, gave higher friction factor. Man et al. [4] developed twisting tapes to be new kinds of this 
passive technique. Then, they studied, through experiments, their effects on flow characteristics and heat transfer for occupied tube by these twisting tapes. Four developed twisting tapes that have lengths of 2400, 1800, 1200 and $600 \mathrm{~mm}$ were covered in authors' experimental study. The water was the working fluid and its flow range was 11335 $\leq \operatorname{Re} \leq 27285$. The given data revealed that the longest twisting tape gave the highest friction factor and Nusselt number higher than those of plain tube by $3.69-5.75$ and $1.45-1.90$ times respectively. Abdolbaqi et al. [5] introduced experimental investigation for studying the characteristics of both flow response and tube heat transfer when double twisting tapes that were installed in counter and cotwisting arrangements. The tapes were twisting at 5 , 10 and 15 twisting ratios, the water was used and it had flow range with Reynolds number from 7200 to 32400. Uniform heat flux was supplied at tube surface. The revealed results showed that the thermal enhancement, friction factor and Nusselt number go to increasing as the tape twisting ratio decreases. Through their obtained data, the authors discovered that the arrangement of counter twist pattern was higher efficient comparing with another arrangement pattern. Li et al. [6] designed a new model of central hollow narrow twisting tape and examined numerically its ability to enhancing heat transfer in laminar flow. Their study covered both the clearance and hollow width effects. They also examined the effect of unilateral number on the performance of heat transfer. For different hollow widths, the given results cleared that the best performance of heat transfer was produced when cross-hollow twisting tape was used. In addition, the authors stated that the unilateral twisting tapes number for giving the better performance of heat transfer was variable and it was related to Reynolds number. As an example, for Re $>600$, this number was 4. Patel and Sagar [7] researched the enhancement in heat transfer and flow characteristics when twisting tapes of different lengths were inserted inside the confined tube. For carrying out the investigation, ANSYS Fluent was used. Turbulent and fully developed flow of air with $4000 \leq \operatorname{Re} \leq 20000$ was supplied at inlet. Their investigation results revealed direct relationships between both Nusselt number and friction factor with the length of twisting tape. Hasanpour et al. [8] studied, by experiments, both friction factor and transferring of heat in heat exchanger when its inner tube has a corrugated surface. This tube was occupied with modified and conventional twisting tapes such as perforated with $\mathrm{V}$ and $\mathrm{U}$ cuts. The considered twisting ratios were 3,5 and 7 . The hole diameters were of ratios of 0.11 and 0.33 . The water was flowed at $5000 \leq \mathrm{Re} \leq 15000$ inside the corrugated tube. For all the cases of insertion twisting tapes, the researchers found that the friction factor and Nusselt number were higher comparing with the given results from empty tube case. Also, the perforated twisting tapes gave lower friction factor and Nusselt number than those given from the case of typical twisting tape. Liu and Bai [9] researched, numerically, the secondary flow helical vortices that generated at tube downstream when $180^{\circ}$ short length twisting tape was inserted at tube upstream. The flow range was $25000 \leq \mathrm{Re} \leq 100000$ with uniform condition at inlet. Their aim was to reveal the formation of these vortices and how they developing. Two symmetric and stable helical vortices were showed downstream. During the development of these vortices, their intensities were decreased. Also, the authors discovered a sharply enlarging in tangential velocities at the pipe wall, but the vortices have a higher decreasing in the center of the pipe. Zhu and Chen [10] studied numerically the effects of insertion twisting tapes on the characteristics of flow and heat transfer in a tube had a boundary of isothermal condition. Single, twin and triplex twisting tape were considered by the authors 
and air was considered as the working fluid which flowed turbulently with $\operatorname{Re} \leq 45000$. The authors concluded that the ability of heat transfer was increased by 1.8-4.5 times with same results for insertion of twin and triplex twisting tapes. Also, it is concluded that these inserts increased the resistant of flow of about 6-21.2 and it was increased as the number of used tapes increased. Chokphoemphun et al. [11] did an experimental investigation to enhance the characteristics of heat transfer and pressure drop of air flow in a circular tube through occupying this tube with deferent numbers of twisting tapes. The air flowed with $5300 \leq \operatorname{Re} \leq 24,000$ and various number of twisting tapes; 1, 2, 3 and 4 with various twist arrangements; co- and counter-twist were covered by this investigation. For single tape, the twist ratio of 4 and 5 was considered, whereas, for the cases of multi tapes, this ratio was 4 only. The authors reported that the results revealed both friction factor and Nusselt number increased by increasing number of twisting tapes and when this number was 4 with counter-twist arrangement, a maximum thermal performance was provided. Eiamsa-ard et al. [12] studied by experiments and numerical simulation the effects of twisting tape of full length and regular space on the behaviors of flow and thermal characteristics of air flow in a tube of heat exchanger. Along this study, the twist ratios $(\mathrm{P} / \mathrm{W})$ of 6 and 8 were selected for all tested twisting tapes and, for twisting tapes with regular space, 1.0, 2.0 and 3.0 were selected as the ratios of free space $(\mathrm{S} / \mathrm{P})$. The air had a turbulent flow at $5000 \leq \operatorname{Re} \leq 12000$. The finding of this article showed an increasing in the target characteristics when the twist and space ratios are decreased, and the full length type twisting tape get better results than the second type. Chang and Huang [13] studied experimentally the enhanced pressure drop and Heat transfer by the use of ribbed twisting tapes of new devised spiky configuration. The study covered these tapes type with edge notches and without them. The twist ratios of $1.56,1.88,2.19,2.5$ and 2.82 were considered and the air flowed through the circular tube with $1000 \leq \operatorname{Re} \leq 40,000$. At $5000 \leq \operatorname{Re} \leq$ 40,000 , the gotten results cleared that the best factor of thermal performance was $0.71-1.31$ which was gotten through using a $\mathrm{V}$-notches spiky twisting tape of flow direction ribs.

\section{Aims of this study}

This previous literature review showed that the using of twisting tapes has a wide consideration in the field of heat transfer enhancement and it still a rich scientific research field. So, this work was done to discover the effect of insertion central cut twisting tape and the tape length on hydrodynamic and thermal fields of turbulent flow.

\section{Physical Model}

Fig. 1 shows a schematic diagram for the geometries of a tube fitted with central cut twisting tapes (CCTT). A negligible thickness horizontal circular tube has diameter (D) of $20 \mathrm{~mm}$ and length (L) of $1000 \mathrm{~mm}$ was occupied with central cut twisting tapes of thickness $(\delta)$ and width $(\mathrm{W})$ of $1 \mathrm{~mm}$ and 18 $\mathrm{mm}$ respectively.
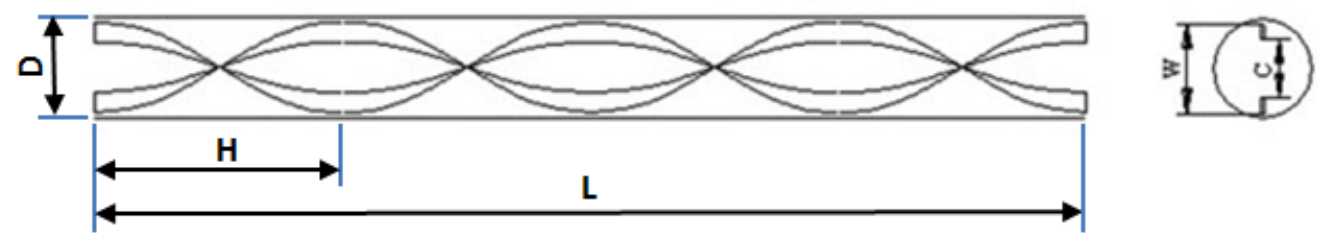

Fig. 1 Schematic diagram of the test rig. 
The studied cases of occupation tube by central cut twisting tapes of different lengths are seen in Fig. 2. These tapes have lengths (1) of 250, 500, 750 and $1000 \mathrm{~mm}$, giving length ratios $(\mathrm{l} / \mathrm{L})$ of $0.25,0.5,0.75$ and 1 respectively. All these twisting tapes have the same central cut width $(\mathrm{C})$ of $8 \mathrm{~mm}$ which forms a central cut ratio $(\mathrm{c}=\mathrm{C} / \mathrm{D})$ of 0.4 . One twisting ratio $(y=H / W)$ of 5 was took in the consideration, where the length $\mathrm{H}$, known as the twist pitch, is the length required for $180^{\circ}$ twist angle, and was of $90 \mathrm{~mm}$ in the present study.

\section{b}

c

Fig. 2 Tube fitted with central cut twisting tape of length ratio; a- 0.25, b- 0.5, c- 0.75 and d- 1 .

Air was selected as the working fluid and it was assumed to be incompressible. No natural convection and temperature independent thermo physical properties of fluid were assumed. The dynamic viscosity $(\mu)$, thermal conductivity $(\mathrm{k})$, density $(\rho)$ and specific heat at constant pressure (Cp) of air were given as $1.7894 * 10-5 \mathrm{~kg} / \mathrm{m} \mathrm{s}$, $0.0242 \mathrm{~W} / \mathrm{m}^{2} \mathrm{~K}, 1.225 \mathrm{~kg} / \mathrm{m}^{3}$ and $1005 \mathrm{~J} / \mathrm{kg} \mathrm{K}$, respectively. The Reynolds number referred to the inlet values were set at 10000, 15000, 20000, 25000, 30000, 35000 and 40000.

\section{Mathematical Model and Numerical Method}

\subsection{Governing Equations}

The considered flow and heat transfer problem is assumed as three dimensional, turbulent and steady. Neglecting heat conduction through twisting tape is also considered. The continuity, momentum and energy equations are:

Continuity equation;

$$
\frac{\partial \bar{u}}{\partial x}+\frac{\partial \bar{v}}{\partial y}+\frac{\partial \bar{w}}{\partial z}=0
$$

(1)

$\mathrm{X}$-direction momentum equation;

$$
\begin{aligned}
& \left(\bar{u} \frac{\partial \bar{u}}{\partial x}+\bar{v} \frac{\partial \bar{u}}{\partial y}+\bar{w} \frac{\partial \bar{u}}{\partial z}\right)+\left(\frac{\partial}{\partial x} \overline{\left(u^{\prime 2}\right)}+\frac{\partial}{\partial y} \overline{\left(u^{\prime} v^{\prime}\right)}+\frac{\partial}{\partial z} \overline{\left(u^{\prime} w^{\prime}\right)}\right) \\
& =-\frac{1}{\rho} \frac{\partial p}{\partial x}+v \nabla^{2} \bar{u}
\end{aligned}
$$

Y-direction momentum equation;

$$
\begin{aligned}
& \left(\bar{u} \frac{\partial \bar{v}}{\partial x}+\bar{v} \frac{\partial \bar{v}}{\partial y}+\bar{w} \frac{\partial \bar{v}}{\partial z}\right)+\left(\frac{\partial}{\partial x} \overline{\left(u^{\prime} v^{\prime}\right)}+\frac{\partial}{\partial y}\left(\overline{v^{\prime 2}}\right)+\frac{\partial}{\partial z} \overline{\left(v^{\prime} w^{\prime}\right)}\right) \\
& =-\frac{1}{\rho} \frac{\partial p}{\partial y}+v \nabla^{2} \bar{v}
\end{aligned}
$$

Z-direction momentum equation;

$$
\begin{aligned}
& \left(\bar{u} \frac{\partial \bar{w}}{\partial x}+\bar{v} \frac{\partial \bar{w}}{\partial y}+\bar{w} \frac{\partial \bar{w}}{\partial z}\right)+\left(\frac{\partial}{\partial x} \overline{\left(u^{\prime} w^{\prime}\right)}+\frac{\partial}{\partial y} \overline{\left(v^{\prime} w^{\prime}\right)}+\frac{\partial}{\partial z} \overline{\left(w^{\prime 2}\right)}\right) \\
& =-\frac{1}{\rho} \frac{\partial p}{\partial z}+v \nabla^{2} \bar{w}
\end{aligned}
$$

Energy equation;

$$
\begin{aligned}
& \bar{u} \frac{\partial \bar{T}}{\partial x}+\bar{v} \frac{\partial \bar{T}}{\partial y}+\bar{w} \frac{\partial \bar{T}}{\partial z}=\alpha \nabla^{2} \bar{T} \\
& -\left(\frac{\partial}{\partial x} \overline{\left(u^{\prime} T^{\prime}\right)}+\frac{\partial}{\partial y} \overline{\left(v^{\prime} T^{\prime}\right)}+\frac{\partial}{\partial z} \overline{\left(w^{\prime} T^{\prime}\right)}\right)
\end{aligned}
$$

The four dimensionless values used in the analysis and comparisons for the obtained results of studied 
cases were Reynolds number (Re), Nusselt number $(\mathrm{Nu})$, friction factor (f) and thermal performance factor (TPF). They defined as follows:

$$
\begin{aligned}
& \operatorname{Re}=\frac{\rho u_{a v} D_{h}}{\mu} \\
& N u=\frac{h D_{h}}{k} \\
& f=\frac{\Delta p}{\left(\rho u_{a v}^{2} / 2\right)(L / D)}
\end{aligned}
$$

Thermal performance factor (TPF), proposed by Webb [14], is the widest used criteria based on the tradeoff between increased heat transfer and friction factor. It is the comparison between the coefficient of heat transfer of the tube fitted with twisting tape and that of plain tube under the condition of same pumping power. It is defined as [15]:

$T P F=\left(N u / N u_{p}\right)\left(f / f_{p}\right)^{-1 / 3}$

(9)

Where, $f_{\mathrm{p}}$ and $N u_{\mathrm{p}}$ are the friction factor and Nusselt number of the plain tube respectively.

\subsection{Boundary Conditions}

A stationary wall conditions for the surfaces of both tube and twisting tapes were applied. The tube wall was assumed to be subjected to constant heat flux. Uniform air velocity and temperature at inlet were considered. Pressure outlet condition is used.

\subsection{Numerical Method}

For the present work, ANSYS Fluent 15 was chosen as the CFD tool. The finite volume method with tetrahedral element was selected to discrete the domain as seen in Fig. (3). For obtaining the results, RNG $k-\varepsilon$ turbulent model was used for solving the present cases. For the pressure field evaluating, the pressure-velocity coupling algorithm SIMPLE (Semi Implicit Method for Pressure-Linked Equations) was selected [16]. A $10^{-6}$ is used as convergence criteria for continuity, velocity components and energy.

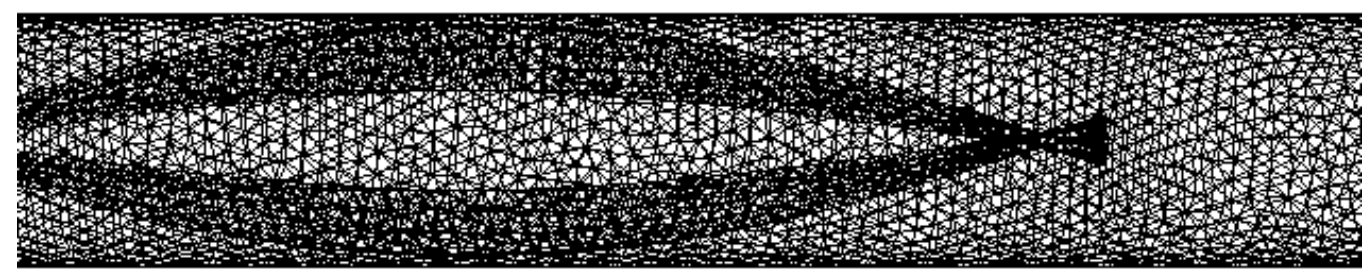

Fig. (3) Tetrahedral mesh generated for tube occupied with central cut twisting tape (CCTT) of LR $=0.5$.

\section{Results and Discussions}

To obtain accurate results, the grid refinement was tested for every case by comparing the obtained results of hydrodynamics and thermal fields of different grids. The chosen grid is that one which has results of less than $1 \%$ deviation from the results of its higher grid.

Table (1) Tested grids and their $N u$ and $f$ results for the studied cases at $\operatorname{Re}=\mathbf{2 5 0 0 0}$.

\begin{tabular}{|c|c|c|c|c|c|c|}
\hline \multirow{2}{*}{ No. } & case & $\begin{array}{c}\text { Mesh } \\
\text { elements }\end{array}$ & $\boldsymbol{N u}$ & $\boldsymbol{N u}$ deviation & $\boldsymbol{f}$ & $\boldsymbol{f}$ deviation \\
\hline \multirow{3}{*}{1} & \multirow{3}{*}{ Plain tube } & 362,245 & 69.5984 & 0.0357 & 0.0256037 & 0.0480 \\
\cline { 3 - 7 } & & 453,526 & 72.17513 & 0.0054 & 0.0268947 & 0.0049 \\
\cline { 3 - 7 } & & 517,497 & 72.56487 & 0.0035 & 0.0270264 & 0.0039 \\
\cline { 3 - 7 } & \multirow{2}{*}{2} & 630,760 & 72.81885 & & 0.0269210 & \\
\hline \multirow{2}{*}{ LR $=0.25$} & 742,164 & 96.42039 & 0.0330 & 0.0473936 & 0.0360 \\
\cline { 3 - 8 } & & 831,028 & 99.71085 & 0.0040 & 0.0491635 & 0.0044 \\
\hline
\end{tabular}




\begin{tabular}{|c|c|c|c|c|c|c|}
\hline & & $1,042,154$ & 100.1113 & 0.0055 & 0.0493808 & 0.0035 \\
\hline & & $1,164,217$ & 100.6619 & & 0.0495536 & \\
\hline \multirow{4}{*}{3} & \multirow{4}{*}{$\mathrm{LR}=0.5$} & 880,693 & 108.0588 & 0.0270 & 0.0545435 & 0.0240 \\
\hline & & 971,189 & 111.0573 & 0.0066 & 0.0558848 & 0.0047 \\
\hline & & $1,168,283$ & 110.3292 & 0.0038 & 0.0561487 & 0.0030 \\
\hline & & $1,301,416$ & 110.7484 & & 0.0559802 & \\
\hline \multirow{4}{*}{4} & \multirow{4}{*}{$\mathrm{LR}=0.75$} & 924,742 & 122.0177 & 0.0230 & 0.0611701 & 0.0320 \\
\hline & & $1,060,616$ & 124.8902 & 0.0042 & 0.0631922 & 0.0031 \\
\hline & & $1,200,744$ & 124.3679 & 0.0032 & 0.0629970 & 0.0025 \\
\hline & & $1,338,752$ & 124.7658 & & 0.0628395 & \\
\hline \multirow{4}{*}{5} & \multirow{4}{*}{$\mathrm{LR}=1$} & 983,179 & 124.8364 & 0.0300 & 0.0618072 & 0.0210 \\
\hline & & $1,105,912$ & 128.6973 & 0.0040 & 0.0631330 & 0.0023 \\
\hline & & $1,231,957$ & 129.2142 & 0.0021 & 0.0632786 & 0.0026 \\
\hline & & $1,376,289$ & 129.4855 & & 0.0634431 & \\
\hline
\end{tabular}

According to the showed results through Table (1), the specified number of elements for the studied cases is as listed in Table (2).

Table (2) Specified number of grid elements

\begin{tabular}{|l|c|}
\hline \multicolumn{1}{|c|}{ Case } & $\begin{array}{c}\text { No. of } \\
\text { elements }\end{array}$ \\
\hline Plain tube & 453,526 \\
\hline $\mathrm{LR}=0.25$ & 831,028 \\
\hline $\mathrm{LR}=0.5$ & 971,189 \\
\hline $\mathrm{LR}=0.75$ & $1,060,616$ \\
\hline $\mathrm{LR}=1$ & $1,105,912$ \\
\hline
\end{tabular}

To exam the accuracy of the present numerical solution, a validation was done through comparing the obtained Nusselt number $(\mathrm{Nu})$ of plain tube with that of Dittus-Boeltor [17] and comparing the obtained friction factor $(f)$ with that of Petukhuv [18]. The present solution has good agreements with acceptable average deviation of $6.1 \%$ for Nesselt number and $8.7 \%$ for friction factor from those authors' results as seen in Fig.s (4 and 5).

Dittus-Boelter correlation [17]:

$N u=0.023 \operatorname{Re}^{0.8} \operatorname{Pr}^{0.4}$

Petukhuv correlation [18]:

$f=(0.79 \ln \mathrm{Re}-1.64)^{-2} \quad 3000 \leq \operatorname{Re} \leq 5 * 10^{6}$

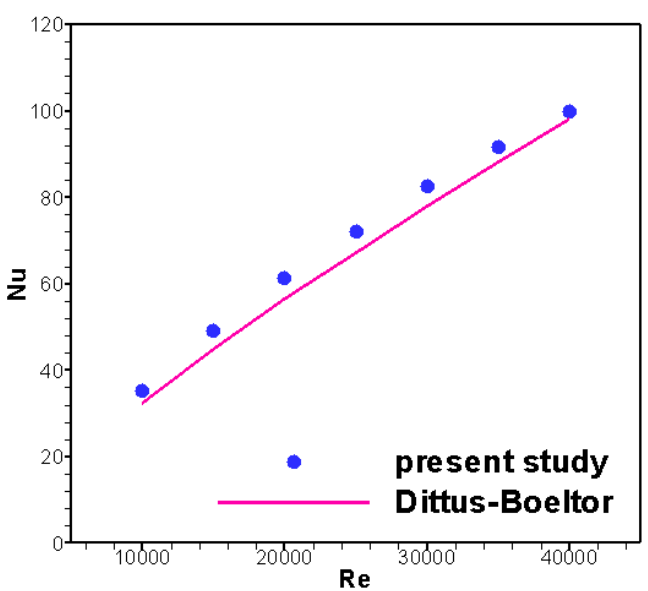

Fig - (4) Validation for Nusselt number for plain tube with Dittus-Boeltor.

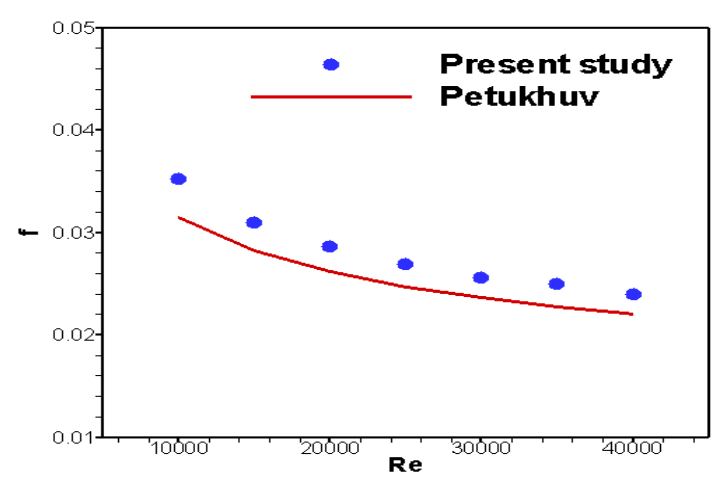

Fig. (5) Validation for friction factor for plain tube with Petukhuv.

As revealed in Fig. (6), insertion of central cut twisting tape will force the flow to leave its axial pattern that showed in frame (A) of this figure, where the flow was confined by plain tube to a swirling pattern, as shown in frames (B to E) of this figure. Also, the comparison of the frames of presence of 
the testing tapes, frames (B to E) proves that as LR be larger, the fluid will flow in stronger swirling pattern for longer axial distance due to increasing in its angular momentum.
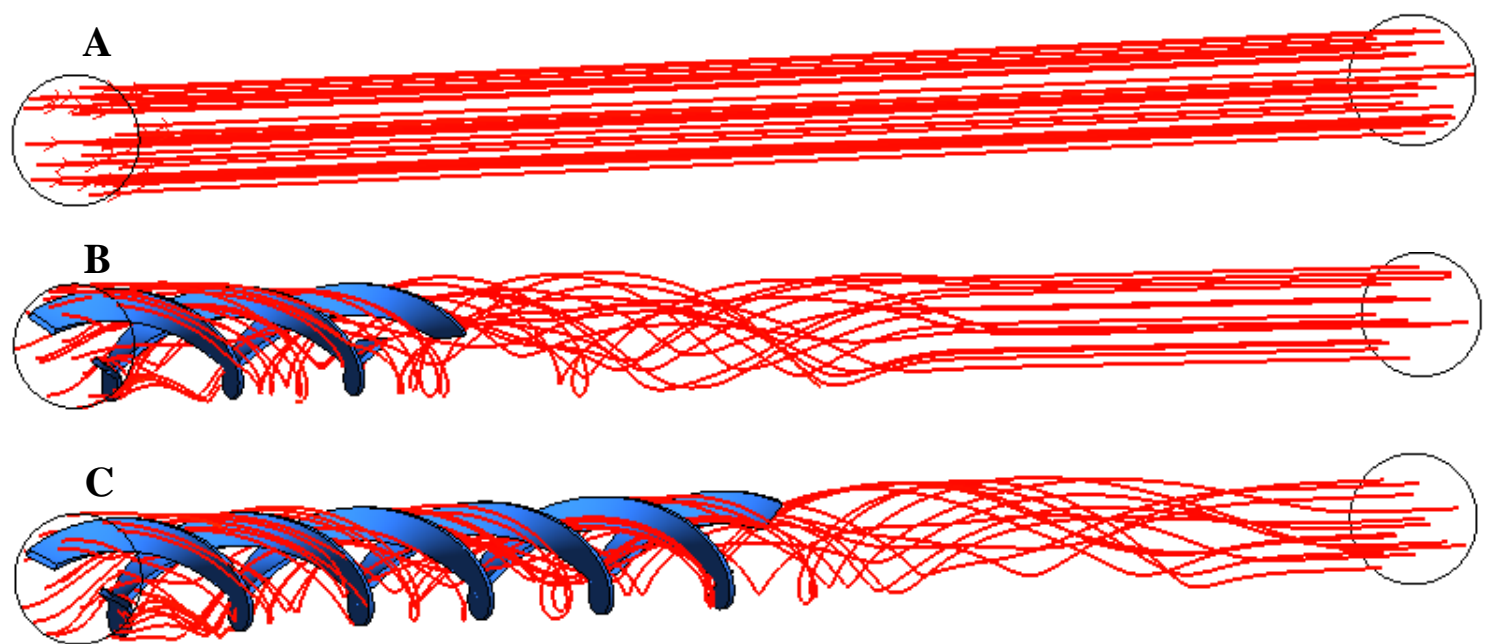

D

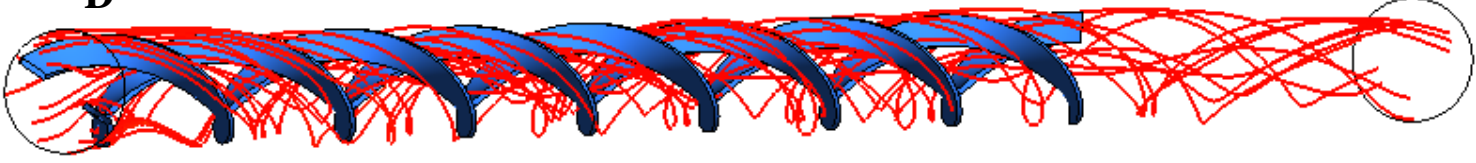

$\mathbf{E}$

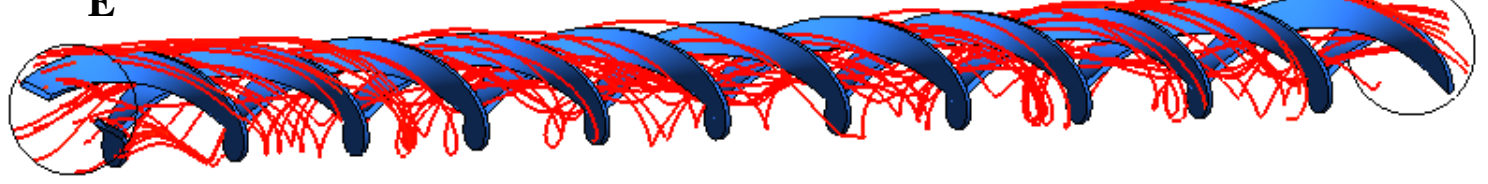

Fig. (6) Pathlines for flow inside the domains of PT (A), $L R=0.25$ (B), LR $=0.5$ (C), $L R=0.75$ (D) and $L R=1(E)$ for $R e=35000$ at axial location of $0.9 \mathrm{~m}$.

The same result will discover when a section of axial distance of $0.9 \mathrm{~m}$ is considered and the flow inside both the plain tube and tube fitted with central

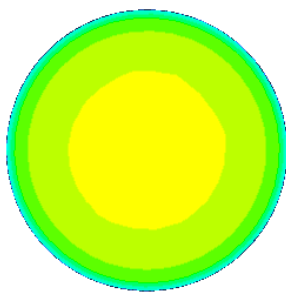

A

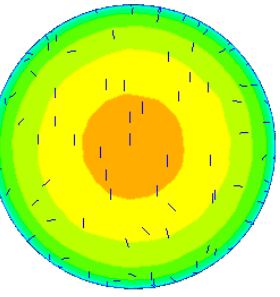

B

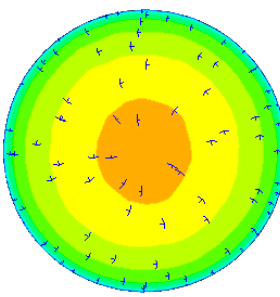

C

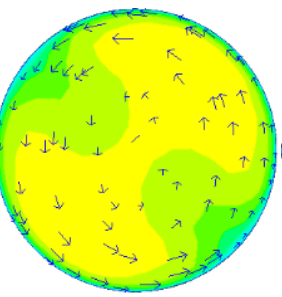

D

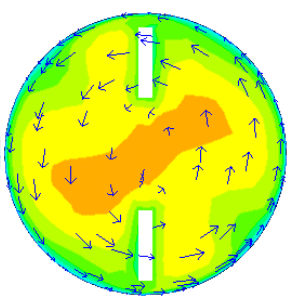

$\mathbf{E}$

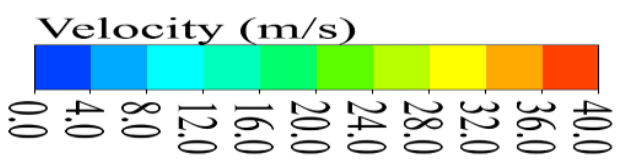

Fig. (7) Vector plot appended on velocity contour for PT (A), $L R=0.25(B), L R=0.5$ (C), LR $=0.75$ (D) and $L R=1(E)$ for $R e=35000$ at axial location of $0.9 \mathrm{~m}$. 
Also, this figure shows that cutting the center of the twisting tape leads to generate two swirl regions and make a central flow region which will enhance the flow mixing.

Swirling flow will prevent the growth of thermal boundary layer which considered as an important limitation in heat transfer. So, the higher level of temperature distribution that appears close to the tube in the case of plain tube, frame (A) in Fig. (8), will disappear in the cases of insertion central cut twisting tapes of different length ratios, frames (B to
E) of the same figure. This is because of the increasing in the angular momentum of the fluid which enables it to transfer from the tube center, the region of lower temperature, to tube surface, the region of higher temperature. This means that there is an increasing in temperature difference between the tube temperature and fluid temperature and, as a result, increasing heat transfer between them. Also, same frames cleared that as LR be larger, the region of lower temperature will increase and tends to reach the tube surface due to increasing in flow mixing.

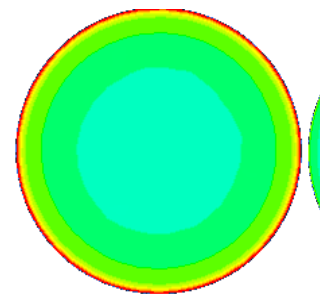

A

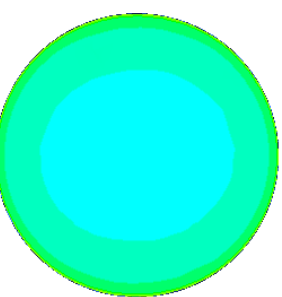

B

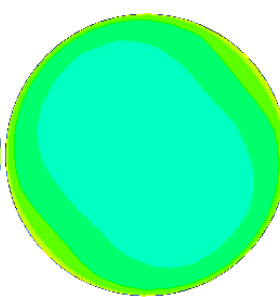

C

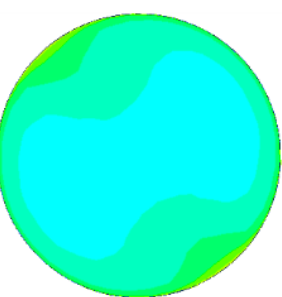

D

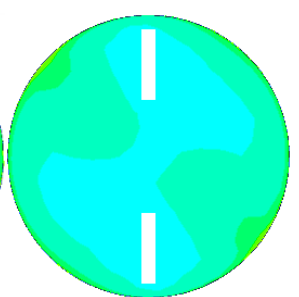

$\mathbf{E}$

Temp. (K)

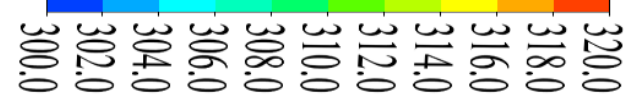

Fig. (8) Temperature contour for PT (A), $L R=0.25(B), L R=0.5(C), L R=0.75$ (D) and $L R=1(E)$ for

\section{$\mathrm{Re}=35000$ at axial location of $0.9 \mathrm{~m}$.}

Insertion central cut twisting tapes inside the tube will obtain Nusselt number higher than that of plain tube as shown through Fig. (9). This increasing is due to the flow blockage and flow mixing which resulted from swirling flow that generated as a result of presence of twisting tapes. Also, this figure shows that there is an increasing in Nusselt number as LR be higher forcing by longer axial distance of swirls generated and increasing in flow blockage. In addition, this figure shows that the Nusselt number will increase by increasing Reynolds number for all studied cases as a result of increasing flow rate. Also, increasing Reynolds number will increase the mixing of fluid between near wall and tube center regions as a result of the increasing in secondary flow kinetic energy, leading to the increasing in the swirl flow, which, of course, will enhance heat transfer.

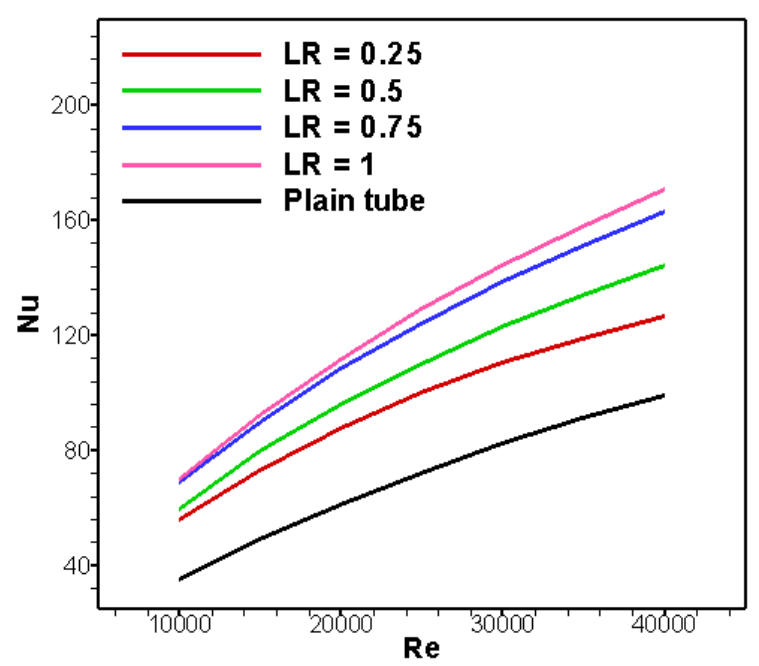


Fig. (9) Variation of Nusselt number with respect to Reynolds number for cases of

\section{different length ratios.}

As cleared in Fig. (10) and followed the pattern of increasing in Nusselt number that were showed in Fig. (9), the Nusselt number ratio will increase by increasing LR of the inserted central cut twisting tape. Also, this figure showed that this ratio will decrease as Reynolds number increases.

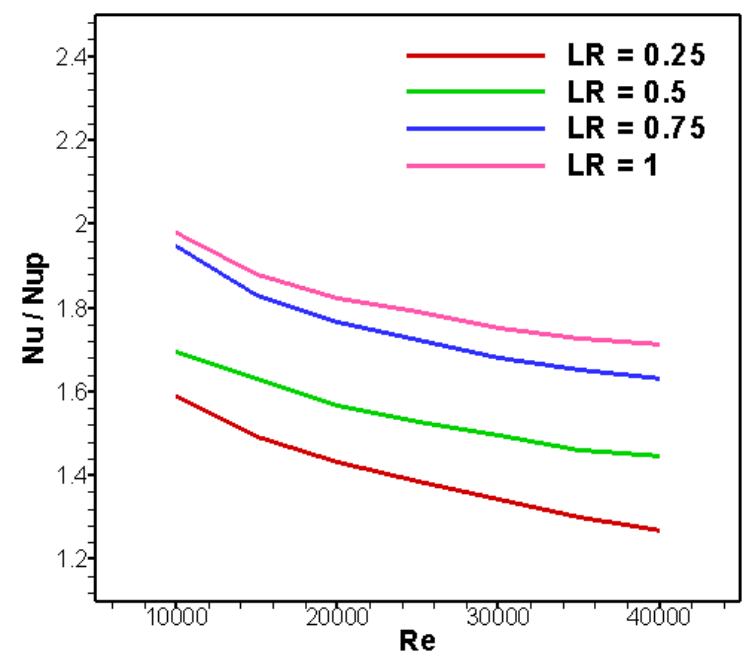

Fig. (10) Variation of Nusselt number ratio with respect to Reynolds number for cases of different length ratios.

Fig.s (11 and 12) show that the adding central cut twisting tapes increases friction factor over than that of plain tube as a result of the increasing in both contact surface area and time residence due to presence of these tapes which leads to increase in shear stresses. Also, these figures show that as LR increases, the friction factor will increase. This is because of the complexity of the flow due to dividing the main flow region, i.e. the flow in plain tube, into numerous regions with different flow types, as a result of insertion of different twisting tapes configurations. In addition, these figures reveal that the lower Reynolds number produces higher friction factor for all studied cases due to decreasing in the flow momentum.

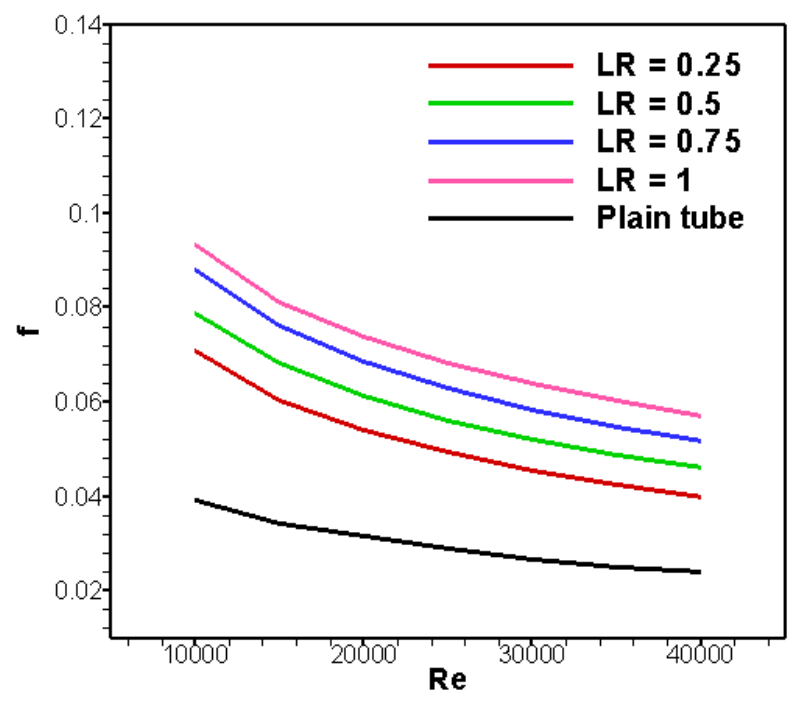

Fig. (11) Variation of friction factor with respect to Reynolds number for cases of different length ratio.

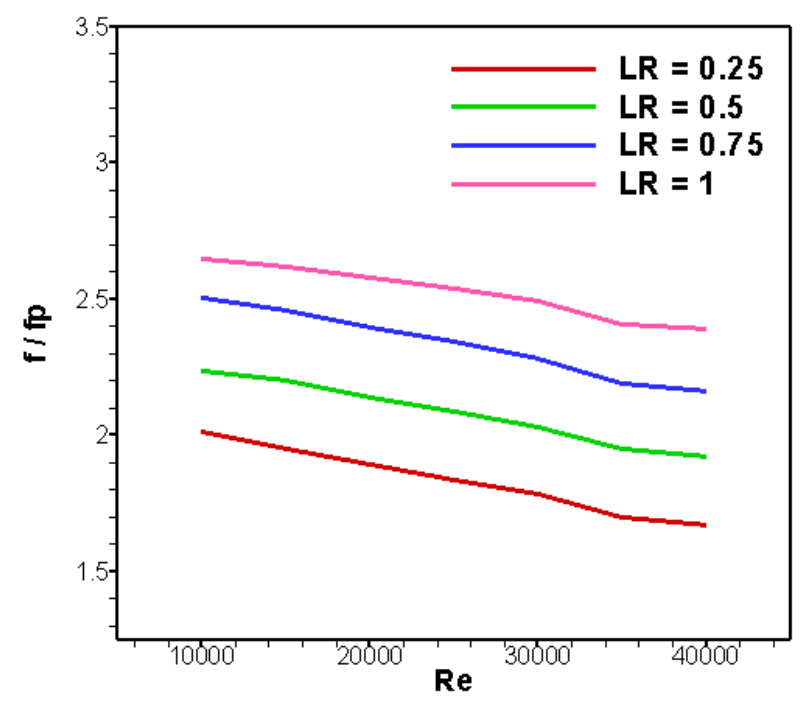

Fig. (12) Variation of friction factor ratio with respect to Reynolds number for cases of different length ratios.

Fig. (13) shows the relationship between thermal performance factor (TPF) and Reynolds number for the studied CCTT cases. As LR increased, this factor increased due to enhanced fluid flow which increases Nusselt number more than increasing in 
friction factor. Generally, this figure shows that adding twisting tape with the studied configurations of different length ratio will reduce viscous stream dominant thermal resistance and the required surface area of heat transfer, leading to saving in the heat exchanger material. The improving thermal performance will accompany by pressure drop increasing [19].

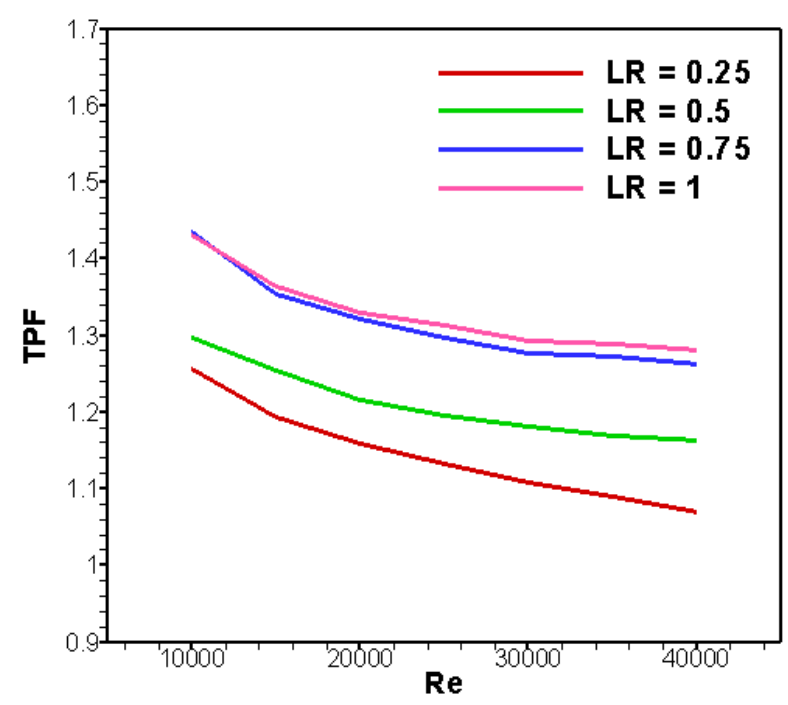

Fig. (13) Variation of thermal performance factor with respect to Reynolds number for cases of different length ratio.

\section{Conclusions}

The turbulent air flow through a tube occupied with central cut twisting tape was performed for cases of different length ratios. It is concluded that:

a- Increasing length ratio increases Nusselt number and its maximum value was 171.172 at $\operatorname{Re}=40000$.

b- Increasing length ratio increases friction factor and its maximum value was 0.0932 at $\operatorname{Re}=$ 10000.

c- Thermal performance factor will increase as the length ratio increases, and its maximum value was 1.432 at $\operatorname{Re}=10000$.

\section{Nomenclature}

C Cut width (mm).

c Cut ratio.

D Tube diameter ( $\mathrm{mm})$.

$\mathrm{D}_{\mathrm{h}} \quad$ Hydraulic diameter $(\mathrm{mm})$.

$f \quad$ Friction factor.

$f_{p} \quad$ Friction factor of plain tube.

$\mathrm{H} \quad$ Length of twisting $180^{\circ}(\mathrm{mm})$.

$h \quad$ Heat transfer coefficient

$\left(\mathrm{W} / \mathrm{m}^{2} \cdot \mathrm{K}\right)$.

$k \quad$ Conductivity (W/m.K).

L Tube length (mm).

$1 \quad$ Twisting tape length ( $\mathrm{mm})$.

$\mathrm{Nu} \quad$ Nusselt number.

$N u_{p} \quad$ Nusselt number of plain tube.

$\mathrm{Pr} \quad$ Prandtl number

LR Length ratio.

Re Reynolds number.

TPF Thermal performance factor.

$u_{a v} \quad$ Flow bulk velocity $(\mathrm{m} / \mathrm{s})$.

$\mathrm{y} \quad$ Twisting ratio.

Greek symbols

$\delta$

Twisting tape thickness (mm).

$\rho \quad$ Density $\left(\mathrm{kg} / \mathrm{m}^{3}\right)$.

$\mu \quad$ Dynamic viscosity (kg/m.s).

\section{References}

1. Suhas V. Patil and P. V. Vijay Babu, "Heat Transfer and Pressure Drop Studies through a Square Duct Fitted with Increasing and Decreasing Order of Twisting Tape", heat transfer engineering vol. 35 nos. (2014) 1415.

2. Jian Guo, Aiwu Fan, Xiaoyu Zhang, Wei Liu, "A numerical study on heat transfer and friction factor characteristics of laminar flow in a circular tube fitted with center-cleared twisting tape", International Journal of Thermal Sciences 50 (2011) 1263-1270. 
3. Qais A. Rishak, Khudheyer S. Mushatet, Mohsen H. Fagr, "Thermal and hydrodynamic characteristics of turbulent flow in a tube with central cut twisting tape: a numerical study", Proc. Of the $2^{\text {nd }}$ Int. Sci. Conf. (1-2 2017) Southern Technical University.

4. Changzhong Man, Jinyu Yao, Chong Wang,

" The experimental study on the heat transfer and friction factor characteristics in tube with a new kind of twisting tape insert", International Communications in Heat and Mass Transfer 75 (2016) 124-129.

5. M.Kh. Abdolbaqi, W.H. Azmi, Rizalman Mamat, N.M.Z.N. Mohamed, G. Najafi, " Experimental investigation of turbulent heat transfer by counter and co-swirling flow in a flat tube fitted with twin twisting tapes", International Communications in Heat and Mass Transfer 75 (2016) 295-302.

6. Pengxiao Li, Zhichun Liu, Wei Liu, Gang Chen, "Numerical study on heat transfer enhancement characteristics of tube inserted with centrally hollow narrow twisting tapes", International Journal of Heat and Mass Transfer 88 (2015) 481-491.

7. Vinay Kumar Patel, N. K. Sagar, "Heat Transfer Enhancement Using Passive Enhancement Technique", International Journal of Engineering Sciences \& Research Technology, Patel, 4(9): September, (2015) 394-399.

8. A. Hasanpour, M. Farhadi, K. Sedighi, "Experimental heat transfer and pressure drop study on typical, perforated, V-cut and U-cut twisting tapes in a helically corrugated heat exchanger", Heat Mass Transfer (2015) http://dx.doi.org/10.1016/j.icheatmasstransf er.2015.12.032.
9. Wen Liu, Bofeng Bai, "A numerical study on helical vortices induced by a short twisting tape in a circular pipe", Case Studies in Thermal Engineering 5 (2015) 134-142.

10. J. D. Zhu , H. Chen, "Numerical Study on Enhanced Heat Transfer by Twisting Tape Inserts inside Tubes", Procedia Engineering 130 (2015) 256-262.

11. Suriya Chokphoemphun, Monsak Pimsarn, Chinaruk Thianpong, Pongjet Promvonge, "Thermal performance of tubular heat exchanger with multiple twisting-tape inserts", Chinese Journal of Chemical Engineering 23 (2015) 755-762.

12. P. Eiamsa-ard a, N. Piriyarungroj b, C. Thianpong b, S. Eiamsa-ard, " A case study on thermal performance assessment of a heat exchanger tube equipped with regularlyspaced twisting tapes as swirl generators", Case Studies in Thermal Engineering 3 (2014) 86-102.

13. Shyy Woei Chang, Bo Jyun Huang, "Thermal performances of tubular flows enhanced by ribbed spiky twist tapes with and without edge notches", International Journal of Heat and Mass Transfer 73 (2014) 645-663.

14. R.L. Webb, "Performance evaluation criteria for use of enhanced heat transfer surfaces in heat exchanger design", Int. J. Heat Mass Transfer 24 (1981) 715-726.

15. Cancan Zhang a, Dingbiao Wang a,n, Kun Ren b, Yong Han a, Youjian Zhu a, Xu Peng a, Jing Deng a, Xiying Zhang a, "A comparative review of self-rotating and stationary twisting tape inserts in heat exchanger", Renewable and Sustainable Energy Reviews 53 (2016) 433-449. 
16. S. Eiamsa-ard, K. Wongcharee, S. Sripattanapipat, "3-D Numerical simulation of swirling flow and convective heat transfer in a circular tube induced by means of loosefit twisting tapes", International Communications in Heat and Mass Transfer 36 (2009) 947-955.

17. Smith Eiamsa-ard, Vichan Kongkaitpaiboon and Kwanchai Nanan, "Thermohydraulics of Turbulent Flow Through Heat Exchanger Tubes Fitted with Circular-rings and Twisting Tapes", Chinese Journal of Chemical Engineering, 21(6) 585-593 (2013).

18. B. S . Petukhov, " Heat Transfer and Friction in Turbulent Pipe Flow with Variable Physical Properties", High Temperature Institrite. Academy of Science of the USSR. Moscow. USSR.

19. Suvanjan Bhattacharyya, Himadri Chattopadhyaya, Indraneel Roy Chowdhuryb and Ayan Haldar, "3D CFD Simulation of Heat Transfer and Friction Characteristics of Laminar Flow of Water through a Circular Duct with Centre-Cleared Twin Twisting Tape", International Journal of Advanced Thermo fluid Research Vol. 1, No. 2, (2015) 60-73. 